\title{
Survey of neonatal screening for primary hypothyroidism in England, Wales, and Northern Ireland 1982-4
}

\author{
D B GRANT, I SMITH
}

\begin{abstract}
National screening for congenital hypothyroidism was established in the United Kingdom in 1982. During 1982-4, 488 infants with primary congenital hypothyroidism were detected by the 25 regional screening laboratories in England, Wales, and Northern Ireland. In addition, one infant had signs of cretinism at birth and was investigated before the screening test was done and four infants were known to have been missed by the screening programme; among these four infants the initial thyroid stimulating hormone concentrations were normal in two with inherited defects of synthesis of thyroxine, not measured in one, and false negative in one. The overall incidence of primary hypothyroidism was $1: 3937$ births (boys 1:6640, girls 1:2756). The incidence seemed to be reduced in infants born to black mothers (two cases only) and increased in those born to Asian mothers (61 cases). Congenital anomalies other than those of the thyroid gland were reported in 36 children $(7 \%)$, and $15(3 \%)$ died from various causes before the age of 4 . Infants who were considered to show unequivocal evidence of hypothyroidism started treatment at a median age of 17 days (5th and 95th centiles 10 and 42 days) compared with a median age of 14 days (5th and 95th centiles 9 and 21 days) for infants with classic phenylketonuria also detected by national screening.
\end{abstract}

Institute of Child Health, London WC1 4NP

D B GRANT, MD, FRCP, consultant endocrinologist, department of growth and development and endocrinology

I SMITH, FRCP, DCH, honorary senior lecturer, department of child health

Correspondence to: Dr Grant.

This paper forms a report for the steering committee for the Medical Research Council's register of children with congenital hypothyroidism, whose members are: Prof J A Davis (chairman), Dr D B Grant and Dr Isabel Smith (register office), Dr G M Addison, Prof A Aynsley-Green, Dr N Barnes, Prof Barbara E Clayton, Mrs Caroline Dore, Prof M A Ferguson-Smith, Prof P J Graham, Dr Margaret Hally (Scottish Home and Health Department), Dr J Hulse, Dr I Lister Cheese and Mr R D Jennings (Department of Health and Social Security), Dr Anne M Jepson, Prof R D G Milner, Prof J G Ratcliffe, Mr D $\mathrm{McI}$ Scott, Prof O H Wolff.

\section{Introduction}

In the United Kingdom neonatal screening for congenital hypothyroidism began in September 1978 in the two North Thames regions, ${ }^{1}$ followed by Scotland ${ }^{2}$ and four more English regions by the end of 1979. In June 1981 the Department of Health and Social Security recommended national screening for congenital hypothyroidism, ${ }^{3}$ and by July 1982 a comprehensive national programme, covering over $99 \%$ of live births, was operating in conjunction with the established programme for phenylketonuria. ${ }^{4} \mathrm{~A}$ register of children with congenital hypothyroidism was set up by the Medical Research Council in January 1982 to monitor the introduction of screening and to permit a prospective follow up study of a cohort of patients. The project was modelled on the Medical Research Council/Department of Health and Social Security Phenylketonuria Register, ${ }^{4}$ with which it maintains close links.

We report on the organisation of screening for congenital hypothyroidism and on the infants in whom the condition was detected from 1982 to 1984 . Using the records up to June 1987, we examined details of the diagnosis, congenital anomalies, deaths, incidence of congenital hypothyroidism among different ethnic groups, and age at which treatment was started compared with that in children with phenylketonuria.

\section{Methods}

Before the start of the study we sent details of the proposed system of notification and follow up of patients to members of the British Paediatric Association, directors of screening laboratories, and regional and district medical officers. We then modified the system to suit the needs of each region. Health boards in Scotland, which had already set up a register, were not included. We asked paediatricians and staff in screening laboratories to notify us of infants whose results of screening tests were positive and in whom hypothyroidism had been confirmed by definitive tests of thyroid function on serum or plasma. We also asked to be notified of patients in whom the condition was first diagnosed on clinical grounds.

After notification of a case the paediatrician was asked to provide further information on a standard questionnaire covering demographic data and details of clinical state, diagnostic investigations (biochemical examinations, radiography of the knee, and thyroid scanning), start of treatment, pregnancy, birth, and family background. Follow up information was requested yearly, and the screening laboratories were also approached yearly to check the accuracy of the preceding year's notifications and for details of 
the number of infants tested and the methods of testing. Data were coded and stored in a computerised database (Scientific Information Retrieval) on the computer (Amadal, IBM) at the University of London.

\section{Results}

\section{ORGANISATION OF SCREENING LABORATORIES}

The Department of Health and Social Security recommended that screening for congenital hypothyroidism should be integrated with the screening programme for phenylketonuria and that negative as well as positive results should be reported so that the district birth registers could be checked to ensure that all newborn infants had been tested. ${ }^{3}$ The recommended time for collecting blood was between the sixth and 14th days after birth. By the end of 1982, 26 laboratories, including one in Scotland (Glasgow) and one at the Royal Army Medical College, Millbank, were performing neonatal screening; this compares with 37 laboratories before 1980-1, when national screening was for phenylketonuria alone. ${ }^{4}$

In eight English regions, Wales, and Northern Ireland (as well as Scotland) one laboratory served the entire health authority; two English regions (North East and North West Thames) were served by the same laboratory; and four regions (Yorkshire, Oxford, Wessex, and West Midlands) were served by two or more laboratories. Seven laboratories in two regions (five in Yorkshire and two in Oxford) tested fewer than 10000 infants each year. All tests for congenital hypothyroidism were performed in dried spots of blood collected on to Guthrie cards; in two laboratories (in North Western and West Midlands regions) an additional specimen of liquid blood was collected into a capillary tube for screening for phenylketonuria by the Scriver test. ${ }^{4}$ Nearly half of the regions used cards of their own design rather than those available from the Department of Health and Social Security.

Twenty three out of 25 screening laboratories (excluding Glasgow) used either a radioimmunoassay or an immunoradiometric assay for thyroid stimulating hormone as the sole method of detecting hypothyroidism. By the end of 1984, 14 laboratories were using one of five commercially available assay kits for thyroid stimulating hormone and 11 were using assays of their own design. The concentration of thyroid stimulating hormone chosen to indicate a positive result ranged from $10 \mathrm{mU} / \mathrm{l}$ in four laboratories to $30 \mathrm{mU} / \mathrm{l}$ in two regional centres. One laboratory (City of Birmingham) measured thyroxine in all specimens in which the thyroid stimulating hormone concentration was $>20 \mathrm{mU} / 1,{ }^{5}$ and another (East Anglia) used a thyroxine assay, combined with an assay for thyroid stimulating hormone on the samples yielding thyroxine concentrations in the bottom fifth of the range, as the primary method of testing.

\section{PATIENTS ON THE REGISTER}

The names of 493 children ( 150 boys, 343 girls) born between 1 January 1982 and 31 December 1984, including 15 who had died and 11 who were lost to follow up, were on the register in June 1987 (figure). Eleven children were kept under review by the local paediatrician because of persistent mild abnormalities of thyroid function, and one child died before treatment could be started; the remainder were recorded as currently receiving treatment with thyroxine. An additional 29 children who were originally entered on to the register were subsequently excluded because the abnormalities of thyroid function were transient. Fifteen children were notified but not entered on to the register because confirmation of the diagnosis or follow up information was not received; some or all of these children could have had hypothyroidism.

Patients missed in screening programme-Four of the 493 patients $(0 \cdot 8 \%)$ on the register had their disease detected not by screening but after they presented with symptoms. Two of these children had had serious medical problems in the neonatal period (tracheo-oesophageal fistula; congenital heart disease and pneumonia) before developing the classic clinical features of congenital hypothyroidism. In one of these children a specimen of blood had not been obtained, but in the other a blood spot was available, which on retesting showed a high concentration of thyroid stimulating hormone. The two other children presented with goitres and other clinical features of hypothyroidism (but not delayed development) due to inherited defects of synthesis of thyroxine; retesting of the original blood spots showed normal concentrations of thyroid stimulating hormone.

\section{CLINICAL DIAGNOSIS OF HYPOTHYROIDISM IN NEONATES}

In 36 infants hypothyroidism had been diagnosed clinically before the abnormal results of screening became known. In 11 of these infants clinical suspicion was high because either a sibling had hypothyroidism (six infants) or the mother had thyroid disease (five). In most of the others the diagnosis was suspected because of persistent neonatal jaundice, but in only one infant were signs of cretinism noted at birth, and in this case the diagnosis was confirmed biochemically before screening was performed.

\section{INVESTIGATION OF PATIENTS ON REGISTER}

Despite recommendation that concentrations of thyroid stimulating hormone and thyroid hormone should be measured in a liquid blood sample to confirm the diagnosis of hypothyroidism before the start of treatment 37 infants started treatment on the basis of an abnormal result of screening alone; in 29 of them a subsequent assay of plasma thyroid stimulating hormone showed concentrations above $10 \mathrm{mU} / \mathrm{l}$ (figure). Definitive tests of

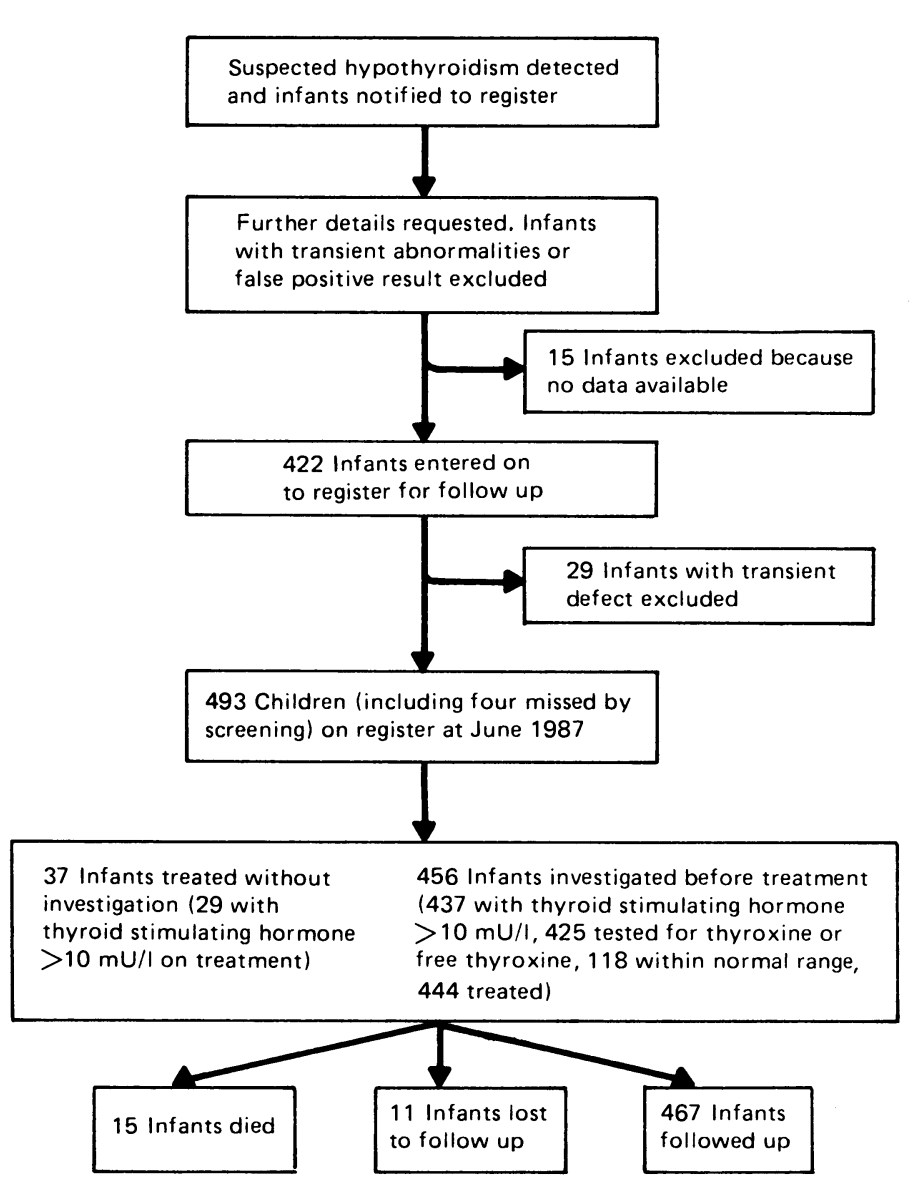

Summary of results of screening programme for congenital hypothyroidism.

thyroid function were performed in 456 infants. Assay of plasma thyroid stimulating hormone (437 infants) showed abnormal concentrations $(>10$ $\mathrm{mU} / \mathrm{l}$ ) in all infants and concentrations above $25 \mathrm{mU} / \mathrm{l}$ in 430 . Plasma concentrations of thyroxine or free thyroxine were measured in 425 infants and were clearly abnormal in only 307 (plasma thyroxine $<70 \mathrm{nmol} / 1$ in 264 infants; free thyroxine $<10 \mathrm{pmol} / \mathrm{l}$ in 43). Of the 118 infants with thyroxine concentrations within the normal range, 112 received treatment with thyroxine.

Congenital anomalies-Of the 493 infants on the register, 36 (7\%) (11 boys and 25 girls) were reported to have congenital anomalies other than those of the thyroid (table I). Although there was no specific pattern of malformations, 12 infants had either cardiac defects or dislocated hips.

Deaths-Fifteen children on the register (3\%) died between the ages of 7 days and 21 months; in the United Kingdom the expected mortality for children aged over 1 week and under 4 years is $0 \cdot 2 \% .{ }^{6}$ Four of the children died of major congenital anomalies (spina bifida (one), prune belly syndrome (one), exomphalos (one), and cardiac defect (one); table 1). Another four died of a severe respiratory disease, which started in the neonatal period. One infant died aged 7 days of enterocolitis; initially the thyroid stimulating hormone concentration was $>200 \mathrm{U} / 1$, and congenital hypothyroidism was confirmed by measurement of serum thyroid stimulating hormone ( $760 \mathrm{U} / \mathrm{l})$. Three children died of cot death. One child died during a febrile illness while 
TABLE I-Congenital anomalies in 493 children with primary hypothyroidism born during $1982-4$

\begin{tabular}{lcll}
\hline Primary anomaly & $\begin{array}{c}\text { No of } \\
\text { children }\end{array}$ & Additional anomalies $\dagger$ \\
\hline Cardiac & $6^{\star}$ & Dysmorphic features (1) \\
Dislocated hip & 6 & Prune belly syndrome (1) \\
Renal & $5^{\star}$ & Choanal atresia (1) \\
Cleft palate & 3 & $3^{\star}$ & \\
Spina bifida or hydrocephalus & 3 & \\
Talipes & 2 & Cardiac defects (2) \\
Down's syndrome & 2 & Rectovaginal fistula (1) \\
Tracheo-oesophageal fistula & 2 & \\
Facial haemangioma & 1 & \\
Anal atresia & $1^{\star}$ & \\
Exomphalos & 1 & \\
Absent fingers & 1 & \\
Glaucoma & & \\
\hline
\end{tabular}

${ }^{\star}$ Death before age 4

†Figures in parentheses are numbers of children

abroad and one of megakaryocytic leukaemia. One child was reported as having internal hydrocephalus, but full details of the cause of death were not available.

Incidence of congenital hypothyroidism overall-The numbers of cases of congenital hypothyroidism on the register were compared with the numbers of live births by region ${ }^{7}$ (table II). The incidence in girls ( 343 of 945159 ; one in 2756) was $2 \cdot 4$ times that in boys ( 150 of 995987 ; one in 6640 ). The overall incidence was one in 3937 , or one in 3821 if the 15 children notified to but not entered on the register were included.

TABLE II-Incidence of congenital hypothyroidism at birth by regional health authority during 1982-4^

\begin{tabular}{lccc}
\hline Region & No of infants & Total No of live births & Incidence \\
\hline Northern & 27 & 117657 & $1: 4358$ \\
Yorkshire & 27 & 138988 & $1: 5148$ \\
Trent & 47 & 171210 & $1: 3643$ \\
East Anglia & 19 & 69594 & $1: 3663$ \\
North East Thames & 25 & 150580 & $1: 6023$ \\
North West Thames & 38 & 137438 & $1: 3617$ \\
South East Thames & 40 & 132488 & $1: 3312$ \\
South West Thames & 23 & 104107 & $1: 4526$ \\
Wessex & 26 & 99682 & $1: 3834$ \\
Oxford & 25 & 93937 & $1: 3757$ \\
South Western & 26 & 107010 & $1: 4116$ \\
West Midlands & 54 & 204842 & $1: 3793$ \\
Mersey & 12 & 63451 & $1: 5288+$ \\
North Western & 58 & 161113 & $1: 2778$ \\
Wales & 26 & 107075 & $1: 4118$ \\
Northern Ireland & 20 & 81974 & $1: 4099$ \\
\hline Total & 493 & 1941146 & $1: 3937$ \\
\hline
\end{tabular}

^Figures include infants missed by screening who presented with symptoms; they exclude infants born to families in the armed forces and resident abroad and infants with transient infants born to families in the armed forces and resident tFor 1983-4 only.

Incidence of congenital hypothyroidism in different ethnic groups-Sixty one children (12\%) had mothers belonging to an Asian ethnic group originating in India or Pakistan; in 58 cases both parents were Asian, in 15 cases being consanguineous. In four further cases the father alone was Asian. Judging from their surnames (assessed by both Moslem and Hindu observers) one third of the Asian infants seemed to be Hindu and two thirds Moslem. In only two cases $(0.6 \%)$ were the mothers reported to be of black (AfroCaribbean) descent; in one the father was also black. In one case the father but not the mother was black. The ratio of boys to girls ( 18 boys, 43 girls) among the infants born to Asian mothers was similar $(1: 2 \cdot 4)$ to that among the infants of non-Asian parents $(1: 2 \cdot 3)$. Despite the high rate of consanguinity evidence of an inherited defect of biosynthesis of thyroid hormone was found in only three of the 24 Asian infants (13) who underwent thyroid scanning compared with 24 of the 159 non-Asian infants (15\%).

\section{START OF TREATMENT}

Excluding the four cases diagnosed solely on clinical grounds, treatment was delayed until after six weeks (range 43-173 days) in 37 infants. In 21 of them treatment was deliberately delayed by the paediatrician as the initial tests of thyroid function showed only borderline abnormalities; in nine, five of whom had been admitted to a neonatal intensive care unit, the blood sample for screening was collected late; and in seven a long, unexplained interval elapsed between the screening test and the diagnostic investigations.

The median age at which children considered to have unequivocal hypothyroidism started receiving treatment was 17 days (5th and 95th centiles 10 and 43 days, respectively) (table III). This compared with a

\begin{tabular}{|c|c|}
\hline Region & Age (days) \\
\hline 1 & $18 \quad(10,41)$ \\
\hline 2 & $17 \cdot 5(10,27)$ \\
\hline 3 & $17 \quad(12,32)$ \\
\hline 4 & $25 \quad(16,38)$ \\
\hline 5 & $27 \quad(18,116)$ \\
\hline 6 & $30 \quad(19,39)$ \\
\hline 7 & $15 \quad(10,62)$ \\
\hline 8 & $20 \quad(11,29)$ \\
\hline 9 & $20 \quad(13,49)$ \\
\hline 10 & $20 \quad(14,69)$ \\
\hline 11 & $17 \cdot 5(11,41)$ \\
\hline 12 & $16(10,54)$ \\
\hline 13 & $15 \quad(13,23)$ \\
\hline 14 & $20 \quad(16,40)$ \\
\hline 15 & $18 \quad(10,68)$ \\
\hline \multirow[t]{2}{*}{16} & $14 \quad(10,58)$ \\
\hline & $17 \quad(10,43)$ \\
\hline
\end{tabular}

${ }^{\star}$ Excludes those in whom hypothyroidism was not diagnosed exclusively by screening or showing borderline results.

median age of 14 days (5th and 95 th centiles 9 and 21 days respectively) in children with classic phenylketonuria also diagnosed by routine neonatal screening from 1982 to 1984 . In the children with congenital hypothyroidism the median age at the start of treatment in each health region ranged from 14 to 30 days (5th centile 10-18 days, 95th centile 23-116 days).

\section{Discussion}

The present study spanned the first three years (1982-4) of national screening for congenital hypothyroidism. The incidence of congenital hypothyroidism in England, Wales, and Northern Ireland was found to be one in just under 4000 births, a figure comparable with that reported for other European countries and North America (from 1 in $3600^{8}$ to 1 in $4148 . .^{9}$ As in all previous studies congenital hypothyroidism was commoner in girls than boys with a male:female ratio of $1: 2 \cdot 3$. The incidence of congenital hypothyroidism seemed to be low in black infants, a finding consistent with a previous report from America. ${ }^{10}$ By contrast, the incidence in Asian infants seemed to be fairly high, although as there are no data on the ethnic background of mothers in the United Kingdom the true incidence of congenital hypothyroidism for the different ethnic groups could not be determined accurately. Although the prevalence of consanguinity between Asian parents was high, congenital hypothyroidism in Asian infants seemed to be due mainly to dysgenesis of the thyroid rather than inherited defects in the synthesis of thyroxine. We are not aware of reports of the incidence of congenital hypothyroidism in the Indian subcontinent.

The incidence of congenital hypothyroidism diagnosed by routine neonatal screening was higher than that expected from retrospective studies of patients in whom the disease had been diagnosed clinically. ${ }^{11}$ This is probably at least partly because most screening programmes can detect mild hypothyroidism associated with large ectopic glands or incomplete defects of synthesis of thyroxine, ${ }^{12}$ which would formerly have presented as juvenile hypothyroidism. Interestingly, almost a quarter of the cases on the register showed increased concentrations of thyroid stimulating hormone associated with plasma thyroxine concentrations in the normal range at diagnosis. The inclusion of infants with transient 
hypothyroidism may also partly explain the fairly high incidence of congenital hypothyroidism, although transient hypothyroidism seems to be uncommon in full term infants in the United Kingdom. ${ }^{13}$ Twenty nine infants who were entered on the register were, however, subsequently excluded because they were shown to have transient hypothyroidism, and other such cases will probably be identified. A retrospective study in Sweden, in which thyroid stimulating hormone was measured in stored blood spots taken before routine testing for hypothyroidism was introduced, showed that one quarter of the children with raised concentrations of thyroid stimulating hormone in the neonatal period had normal thyroid function at follow up. ${ }^{14}$ In a letter sent to paediatricians early in 1982 when the register was set up we emphasised the need to withdraw treatment temporarily some time after the age of 1 year, particularly for children without clinical features of hypothyroidism or in whom thyroid function was borderline at diagnosis. The records of the register suggest that this advice was heeded to only a limited extent.

An important observation was that mortality among the children was unexpectedly high, being over 10 times higher than that in the general population of the United Kingdom during the first four years of life. Respiratory illness and congenital malformations accounted for some but not all of the increase. The incidence of congenital malformations was $7 \%$, about three times that in the general population. ${ }^{15}$ The findings are consistent with dysgenesis of the thyroid being part of a range of teratogenic events in early gestation and raise the possibility that congenital hypothyroidism could contribute more to neonatal deaths than is generally recognised. An increased incidence of congenital malformations has been reported previously in infants with congenital hypothyroidism. ${ }^{16} 17$

In the first three years of screening (based mainly on measurement of thyroid stimulating hormone) four patients with primary hypothyroidism $(0 \cdot 8 \%)$ were known to have been missed. This is a similar proportion to that missed in the screening programme for phenylketonuria ${ }^{4}$ and was similar to that recently reported from North America.$^{18}$ Earlier screening programmes reported an incidence of missed cases of hypothyroidism of $2 \cdot 5-6 \cdot 8 \% .{ }^{1920}$ In this screening programme the omission of two cases (one in which a blood specimen was not taken and one in which a false negative result was obtained) might have been prevented, but the two other infants, who presented with goitres due to defects of thyroxine synthesis, had normal thyroid stimulating hormone concentrations at screening.

In this study over a quarter of the infants detected as having congenital hypothyroidism by screening (mainly measurement of thyroid stimulating hormone) had plasma thyroxine concentrations within the normal range. This may help to explain the fairly high proportion of infants missed on initial testing in a screening programme based on measurement of thyroxine ${ }^{21}$ : although the $10 \%$ of infants with the lowest plasma thyroxine concentrations were initially recalled for investigation, which resulted in the diagnosis of congenital hypothyroidism in 163 among 811917 newborn infants. A second screening of 484604 of the infants at 6 weeks of age detected a further 19 cases. A second test was thus concluded to be justified on economic grounds. The small number of missed cases identified in our survey suggests that far fewer false negative results will occur with measurements of thyroid stimulating hormone and that the benefits of a second screening test would be small. Nevertheless, other missed cases may yet be discovered as no screening system can be perfect. Paediatricians should test promptly for hypothyroidism in children with delayed development or in whom hypothyroidism is suspected on other clinical grounds.

The median age of 17 days at which children with congenital hypothyroidism started treatment compares favourably with that in other screening programmes. ${ }^{22} 23$ This age, however, was higher than that for children with phenylketonuria. In 3\% of infants with congenital hypothyroidism treatment was delayed beyond 6 weeks of age either because of late screening or because of an unexplained delay between the initial test and the diagnostic investigations. An appreciable proportion of these children, and the child in whom the diagnosis was missed because no test was done, had been admitted to special care neonatal units with life threatening conditions (which seemed to be more common in the children with hypothyroidism than in the general population), and this might easily interfere with routine screening tests, as reported elsewhere..$^{24}$

The age at which treatment started varied considerably among regions, suggesting that improvements could be made, particularly in the time taken to respond to a positive result of screening. Retrospective studies suggest that intelligence in children with congenital hypothyroidism is normal provided that treatment is started within six weeks after birth, ${ }^{25}$ and the results of a pilot prospective study showed no relation between the age at starting treatment and intelligence at 3 years. ${ }^{26}$ Initial analysis of a collaborative European study suggested, however, that even a short delay in starting treatment may impair outcome in infants with athyreosis. ${ }^{27}$ Children on the register will undergo psychometric and behavioural assessment when they reach 5 years, which should provide further information on this important point.

The committee thanks all those who provided information to the register over the past five years, in particular directors of screening laboratories and their staff, consultant paediatricians, and community physicians; it also thanks the families whose children are participating in the follow up study.

\section{References}

1 Hulse JA, Grant DB, Clayton BE, et al. Population screening for congenital hypothyroidism. Br Med f 1980;280:675-8.

2 Sutherland RM, Ratcliffe JG, Kennedy R, Stevenson JS, Patrick MJ, Ferguson-Smith MA. Neonatal screening for hypothyroidism in Scotland: results of a pilot study. Scott Med $1981 ; 26: 229-34$

Department of Health and Social Security. Screening for early detection of congenital hypothyroidism London: DHSS, 1981. (HN(81)20.)

4 Medical Research Council Steering Committee for the MRC/DHSS Phenylketonuria Register. Routine neonatal screening for phenylketonuria in the United Kingdom 1964-78. Br Med 1981;282:1680-4.

5 Griffiths KD, Virdi NK, Rayner PHW, Green A. Neonatal screening for congenital hypothyroidism by measurement of plasma thyroxine and thyroid stimulating hormone concentrations. BrMed f 1985;291:117-20.

6 Office of Population Censuses and Surveys. Mortality statistics: England and Wales. London: HMSO, 1984.

7 Office of Population Censuses and Surveys. Birth statistics. London: HMSO, 1982, 1983, 1984

8 Delange F, Illig R, Rochiccioli P, Brock-Jacobsen B. Progress report 1980 on neonatal hypothyroid screening in Europe. Acta Paediatr Scand 1981;70:1-2.

9 New England Congenital Hypothyroidism Collaborative. Effects of neonatal screening for hypothyroidism: prevention of mental retardation by treatment before clinical manifestations. Lancet 1981 ;ii: 1095-8.

0 Brown AL, Fernhoff PM, Milner J, McEwen C, Elsas LS. Racial differences in the incidence of congenital hypothyroidism. I Pediatr 1981;99:934-6.

1 Alm J, Larsson A, Zetterstrom R. Congenital hypothyroidism in Sweden. Incidence and age at diagnosis. Acta Paediatr Scand 1978;67:1-3.

12 Hulse JA, Jackson D, Grant DB, Byfield PGH, Hoffenberg R. Different measurements of thyroid function in hypothyroid infants diagnosed by screening. Acta Paediatr Scand 1979;277 suppl:21-5.

13 Hulse JA, Grant DB, Jackson D, Clayton BE. Growth, development, and reassessment of hypothyroid infants diagnosed by screening. Br Med f 1982;284: 1435-7.

14 Alm J, Hagenfeldt L, Larsson A, Lundberg K. Incidence of congenital hypothyroidism: retrospective study of neonatal laboratory screening versus clinical symptoms as indicators retrospective study of neonatal laboratory scree
leading to diagnosis. BrMed f 1984;289:1171-5.

15 Marden PM, Smith DW, McDonald MJ. Congenital anomalies in the newborn infant, including minor variations. I Pediatr 1964;64:357-71.

16 Bamforth JS, Hughes I, Lazarus J, John R. Congenital anomalies associated with hypothyroidism. Arch Dis Child 1986;61:608-9.

17 Goujard J, Safar A, Rolland A, Job JC. Épidémiologie des hypothyroidies congénital malformitives. Arch Fr Pediatr 1981;38:875-9.

18 Holtzman C, Slazyk WE, Cordero JF, Hannon WH. Descriptive epidemiology of missed cases of phenylketonuria and congenital hypothyroidism. Pediatrics 1986; 78:553-8.

19 New England Congenital Hypothyroidism Collaborative. Pitfalls in screening for neonata hypothyroidism. Report of the New England screening program and the New England hypothyroidism. Report of the New England screening program

20 Pitt D, Connelly J, Francis I, et al. Genetic screening of newborn in Australia: results for 1981 Med J Aust 1983;1:333-5.

21 La Franchi SH, Hanna CE, Krainz PL, Skeels MR, Miyahira RS, Sesser DE. Screening for congenital hypothyroidism with specimen collection at two time periods: results of northwest regional screening program. Pediatrics 1985;76:734-40.

22 Price DA, Ehrlich RM, Walfish PG. Congenital hypothyroidism. Clinical and laboratory characteristics in infants detected by neonatal screening. Arch Dis Child 1981;56:845-51.

23 New England Congenital Hypothyroidism Collaborative. Characteristics of infantile hypothyroidism discovered on neonatal screening. $\mathcal{F}$ Pediatr 1984;104:539-44

24 Fernhoff PM, Brown AL, Elsas JL. Congenital hypothyroidism: increased risk of neonatal morbidity results in delayed treatment. Lancet 1987;i:490-1.

25 Macfaul R, Dorner S, Brett EM, Grant DB. Neurological abnormalities in patients treated for hypothyroidism from early life. Arch Dis Child 1978;53:611-9.

26 Murphy G, Hulse JA, Jackson D, et al. Early treated hypothyroidism: development at 3 years. Arch Dis Child 1986;61:761-5.

27 Illig R, Largo RH, Qin Q, Torresani T, Rochiccioli P, Larsson A. Mental development in congenital hypothyroidism after neonatal screening. Arch Dis Child 1987;62:1050-5.

(Accepted 28 October 1987) 